\title{
Introduction au dossier critique : Histoire (1967)
}

\section{Anne-Yvonne Julien}

\section{OpenEdition}

\section{Journals}

Édition électronique

URL : http://journals.openedition.org/ccs/670

DOI : $10.4000 /$ ccs. 670

ISSN : 2558-782X

\section{Éditeur :}

Presses universitaires de Rennes, Association des lecteurs de Claude Simon

\section{Édition imprimée}

Date de publication : 31 décembre 2010

Pagination : 23-27

ISBN : 9782354120771

ISSN : 1774-9425

\section{Référence électronique}

Anne-Yvonne Julien, «Introduction au dossier critique : Histoire (1967)», Cahiers Claude Simon [En ligne], 6 | 2010, mis en ligne le 21 septembre 2017, consulté le 24 septembre 2020. URL : http:// journals.openedition.org/ccs/670; DOI : https://doi.org/10.4000/ccs.670 


\section{Dossier critique Histoire (1967)}



Comment est-il possible que de tant d'histoires ou plutôt fragments d'histoires, superposés ou enchevêtrés, il subsiste une histoire et qui plus est, inscrite dans l'Histoire ou du moins dans les réseaux aussi complexes que confus de l'Histoire ? Est-il imaginable d'ailleurs qu'un moi indubitablement vivant ait pu sortir de ces cohortes de " fantômes bâillonnés par le temps " ? Question lancinante assurément, portée, d'une certaine manière, par la narration du roman Histoire de Claude Simon, si significativement interrompue par un point interrogatifque prolongent trois points de suspension.

La critique simonienne l'a souvent souligné, ce roman est une étape dans l'œuvre de l'écrivain, une frontière entre les textes des années cinquante et du début des années soixante, certes déroutants dans la phase de leur réception - mais où le coup d'œil rétrospectif de l'analyste décèle une couleur relativement unitaire -, et les textes des années soixante dix, qui se signalent par des audaces formelles particulièrement vives. Ici déjà, le dessin imputable au tressage des séquences ne se laisse pas si aisément appréhender et le lecteur doit faire l'effort d'entrer dans ce discours qui perd le fil, le retrouve, en saisit un autre, le lâche, puis un autre encore, creusant des sillons temporels multiples.

Le critique Ralph Sarkonak notait en 2000 combien la position centrale occupée par Histoire au sein de «l'arborescence » de l'œuvre était « devenue plus visible encore après la parution en 1997 duJardin des Plantes $»^{1}$, mais le lecteur qui a désormais découvert Le Tramway

Claude Simon 3, Lectures d'Histoire, textes réunis et présentés par Ralph Sarkonak, La Revue des Lettres modernes, Minard, 2000, p. 5. 
(2001) peut aussi positionner en regard le roman de 1967 et le dernier récit. Combien de visions obsédantes ou parfois illuminantes ces deux textes ont-ils en partage : la mère dans les derniers mois au visage émacié de "lame de couteau ", les courses essoufflées du jeune collégien, le « silencieux bruissement nocturne de la mer », la lumière jaunâtre de fin d'été... Un peu comme si Le Tramway était devenu l'aile la plus avancée d'Histoire, sa réduction à l'essentiel : Histoire fait de tout signe métaphore dérivante, pour glisser d'une sphère mémorielle ou perceptive à une autre ; Le Tramway assure, pour sa part, le transport de l'anamnèse sur des mécaniques roulantes plus épurées, plus élémentaires encore, tramway ou lit d'hôpital...

Ici seront proposées deux lectures d'Histoire qui veulent, chacune à leur manière, se préoccuper de la question générique. Certes, il ne s'agit pas d'imposer au texte de Simon des modèles avec lesquels son œuvre a cherché à rompre ; mais plus précisément de concevoir une interrogation fondée sur la confrontation d'un texte d'une autonomie souveraine avec des formes répertoriées du littéraire en faisant l'hypothèse que ce détour peut éclairer la spécificité du geste d'écriture simonien.

S'il n'est pas contestable qu'Histoire mette en échec la formule du roman historique, associée au paradigme réaliste, il vaut cependant de se pencher sur le mode d'articulation qui s'y décèle entre matériau historique et récit déchronologisé. Tel est l'axe de l'interrogation de Wolfgang Asholt qui veut prendre en compte, dans sa réflexion, la crise du récit historique du second vingtième siècle, le rôle accordé par les théoriciens allemands de la memoria au littéraire et les hypothèses de Ricœur sur le " quasi-passé de la fiction » comme vecteur de "possibles enfouis dans lepassé effectif». Il y aurait ainsi porosité entre les expériences de la mémoire privée et celles d'une mémoire collective du siècle. Et la séquence des premières semaines de la guerre d'Espagne à Barcelone figurerait la référence centrale pour le travail du deuil de la "presque mémoire " qu'entreprend Histoire, le présent élastique de la narration, devenant voie d'accès aux nœuds les plus complexes d'une Histoire partagée. (U. d'Osnabrück)

Pour poser la question des fonctions du mythe dans Histoire, Antonin Wiser se saisit, à titre instrumental, de la notion de " naïveté épique » élaborée par Theodor Adorno à l'époque des travaux préparatoires à La Dialectique de la raison (1944). L'épique selon 
Adorno s'attache au particulier et à la naissance d'un sujet en butte aux puissances archaïques qui le menacent et, si sa force d'expression peut être qualifiée de " naïve ", c'est qu'elle échappe à la contrainte logique du récit en préférant la parataxe à la syntaxe. Histoire peut être lue avec cette grille : s'y décrypterait l'itinéraire chaotique d'un Télémaque, soucieux de la question des origines et des traces laissées par un Ulysse paternel vagabond ; d'un fils assailli par les puissances mythiques dissolvantes, Lotophages, Circé et autres sirènes, tentations plurielles de fuite ontologique ou de retour à la nuit matricielle. Expériences au bord de l'irreprésentable et qui pourtant trouvent dans les marges d'une mythologie revisitée et souvent ironisée, un langage pour subsister comme savoir narratif, un langage qui, si « naïf» soit-il, s'accorde à la quête d'un moi problématique, préservé de la vanité de tout logocentrisme. (U. de Lausanne et de Paris IV Sorbonne).

A.-Y. J. 